\title{
Carcinogenic Hydrocarbon
}

National Cancer Institute

\section{Source}

National Cancer Institute. Carcinogenic Hydrocarbon. NCI Thesaurus. Code C44351.

An organic compound that is likely to cause cancer and contains only carbon and hydrogen that can be arranged in rows, rings, or both, and connected by single, double or triple bonds. Carcinogenic hydrocarbons are often found in petroleum, natural gas and coal and are capable of causing cancer. ( $\mathrm{NCl05)}$ 